\title{
Geographical variation in wolf spider dispersal behaviour is related to landscape structure
}

\author{
DRIES BONTE*, JEROEN VANDEN BORRE*, LUC LENS* \& JEAN-PIERRE MAELFAIT† \\ ${ }^{*}$ Department of Biology, Terrestrial Ecology Unit, Ghent University, Ghent \\ $\dagger$ Institute of Nature Conservation, Brussels \\ (Received 9 August 2005; initial acceptance 14 October 2005; \\ final acceptance 24 November 2005; published online 28 July 2006; MS. number: 8651R)
}

\begin{abstract}
Theoretical studies suggest that mechanisms underlying habitat and population structure are important for shaping inter- and intraspecific variation in dispersal behaviour. Empirical evidence, especially in organisms living in spatially structured populations, however, is scarce. We investigated the relation between habitat configuration (patch size, connectivity) and dispersal by studying variation in tiptoe behaviour in the dune wolf spider, Pardosa monticola, under standardized laboratory conditions. Tiptoe behaviour prepares spiderlings for ballooning and can hence be considered as a precursor of aerial dispersal. The proportion of individuals that displayed tiptoe behaviour was highest in offspring from grasslands in a large dune landscape where habitat was continuously available, intermediate in offspring originating from a fragmented landscape, and lowest in offspring originating from a small and extremely isolated grassland patch. At the level of the fragmented landscape, variation was related to size and connectivity of four subpopulations. Both between and within landscapes, maternal condition had no effect on offspring dispersal. These results indicate that changes in habitat configuration from a large, connected landscape towards a small, fragmented one may lead to a decrease in dispersal rates, even at small spatial scales. Hence, behavioural traits narrowly linked to dispersal evolve towards less mobile phenotypes in small, isolated habitats, indicating high dispersal costs and low efficacy for gene flow in a spider species restricted to fragmented habitats.
\end{abstract}

(c) 2006 The Association for the Study of Animal Behaviour. Published by Elsevier Ltd. All rights reserved.

Theoretical and empirical studies suggest that dispersal, that is, one-way movements to breeding locations away from the place of birth (Dingle 1996), is favoured by natural selection through kin competition, inbreeding avoidance and temporal variability in habitat quality, and counterselected by stable environmental heterogeneity and niche specialization (reviewed in Clobert et al. 2001; Bullock et al. 2002). However, these relations have mainly been derived from studies on active dispersers, that is, organisms that control the direction and/or distance of dispersal, such as most vertebrate species (e.g. Greenwood et al. 1978; Ims 1990; Sorci et al. 1994; Negro et al. 1997; Massot $\&$ Clobert 2000) and winged invertebrates (e.g. Den Boer 1970; Roff 1997; Komonen et al. 2004). Unlike winged arthropods, spiders (Araneae) and mites (Acaridae) often perform aerial dispersal in a predominantly uncontrolled mode (e.g. Weyman 1993; Weyman et al. 2002), thereby entering suitable habitats largely by chance (Bell et al. 2005).

Correspondence: D. Bonte, Department of Biology, Terrestrial Ecology Unit, Ghent University, K.L. Ledeganckstraat 35, B-9000 Ghent, Belgium (email: dries.bonte@ugent.be).J.-P. Maelfait is at the Institute of Nature Conservation, Kliniekstraat 25, B-1070 Brussels, Belgium.
Under such conditions, average costs of dispersal can be expected to be high and natural selection can be expected to favour philopatry, particularly under high levels of habitat specialization (Den Boer 1970; With et al. 1997; Bonte et al. 2003d) and/or habitat isolation (Southwood 1962; With et al. 1997; Dieckmann et al. 1999).

Whereas population and quantitative genetic studies have demonstrated extensive geographical adaptive variation in nonbehavioural traits (Foster 1999), evolutionary studies on geographical variation in behavioural traits are still scarce. Nevertheless, such studies offer the best hope for dissecting behavioural adaptations (Arnold 1992; Foster 1999) because geographical variation in behaviour may evolve over relatively short time frames (Riechert 1999). At present, the genetic component underlying aerial dispersal in wingless arthropods is poorly known, but the presence of genetic variation has been documented in mites (Li \& Margolies 1993, 1994) and spiders (Bonte et al. 2003b). Selection for aerial dispersal has been reported for species occupying rare habitats (but not unstable or predictable ones; Richter 1970) and for generalist species (Bonte et al. 2003d). In anemochorous plants, habitat isolation selects against dispersal-related seed traits 
(Carlquist 1966; Cody \& Overton 1996). These heterogeneous results suggest the existence of, and interaction between, multiple selective forces, whether or not combined with proximate determinants such as weather conditions, food shortage or crowding (reviewed in Weyman et al. 2002). Apart from natural selection, condition-dependent maternal effects may cause variation in life history traits within spatially structured populations (Ims \& Hjermann 2001). This can be expected when phenotypic specialization takes place at an early ontogenetic stage and/or when offspring are not capable of directly perceiving cues from the external environment. Under such conditions, a maternal link in the pathway of condition-dependent dispersal may indirectly convey information about the environment (Ims \& Hjermann 2001) and, as such, determine offspring dispersal rates (De Fraipont et al. 2000).

We examined how propensity for aerial dispersal in offspring of the dune wolf spider, Pardosa monticola Clerck 1757, varies in relation to the spatial configuration of dune grasslands. As in all species of wolf spiders, physical constraints restrict aerial dispersal during the first two (sometimes three) instars (Richter 1970; Bell et al. 2005) and maternal effects may preadapt offspring to the ambient conditions they are likely to encounter in their natal habitat at later stages. We studied propensity for aerial dispersal under standardized laboratory conditions (i.e. by quantifying the occurrence of series of stereotyped behaviours preceding take-off, termed tiptoe behaviour; Weyman 1993) at two spatial scales. The prevalence of this behaviour is a good precursor of effective aerial dispersal (Weyman et al. 1995; D. Bonte, unpublished data), although we cannot separate inter- and intrapopulation dispersal, as this is determined by wind velocity (Bell et al. 2005). We studied variation in tiptoe behaviour among offspring originating from females collected in three areas of dunes differing in population structure (continuous, fragmented and isolated populations) and among four subpopulations of the fragmented population from the Flemish coast (Bonte et al. 2003c).

We conducted laboratory experiments to test the following predictions. (1) Aerial dispersal is highest in offspring originating from large, continuous landscapes consisting almost entirely of suitable habitat and lowest in offspring originating from strongly isolated populations. (2) Within fragmented landscapes, local variation in aerial dispersal is determined by local patch size and connectivity. (3) Variation in tiptoe behaviour does not depend on maternal reproductive traits. Because maternal reproductive traits correlate with habitat quality, the latter were retained as maternal-condition covariates (Toft 1999; Hendrickx et al. 2003), thus providing insights into maternal habitat quality.

\section{METHODS}

\section{Study Areas}

During June-July 2003, we collected P. monticola females with eggsacs in three dune regions: North-Holland dune reserve (NHD, Netherlands, Bergen-aan-zee, $52^{\circ} 38^{\prime} \mathrm{N}, 4^{\circ} 37^{\prime} \mathrm{E}$ ), Flemish coastal dunes (FCD, Belgium, De Panne-Ghyvelde, $51^{\circ} 05^{\prime} \mathrm{N}, 2^{\circ} 32^{\prime} \mathrm{E}$ ) and inland dunes of Moerbeke (IDM, Belgium, $51^{\circ} 11^{\prime} \mathrm{N}, 3^{\circ} 55^{\prime} \mathrm{E}$ ). Grasslands in all three areas comprise mesophytic vegetation and are dominated by low grasses, sedges and herbs (see Bonte \& Maelfait 2001 for further details). In the Flemish coastal dunes, four spatially structured subpopulations were studied in detail during June-July 2002.

The three dune districts differed in their configuration of grassland patches. In area NHD, we sampled female P. monticola in a continuous grassland patch of 400 ha (Wimmenummerduinen near Egmond, Zumkehr 2001). This area is referred to below as continuous landscape. In area FCD, grassland patches were an average \pm SE of $1.41 \pm 0.41$ ha and showed moderate levels of patch connectivity (as defined by Bonte et al. 2003c; that is, a species-specific combination of geographical isolation and permeability of the surrounding matrix). In this area (fragmented landscape), we sampled $P$. monticola females in four isolated fragments with the following characteristics: fragment 1: area 1.2 ha, connectivity 10.21; fragment 2: area 0.85 ha, connectivity 9.36; fragment 3: area 0.16 ha, connectivity 7.66; fragment 4 : area 0.30 ha, connectivity 7.89 (Bonte et al. 2003c). All four fragments, as well as populations in NHD and IDM, were embedded within shrub or woodland vegetation which represents a hostile matrix for $P$. monticola that renders cursorial movements impossible (Bonte et al. 2004). In area IDM, we sampled females in a strongly isolated grassland patch of 0.48 ha (no other populations within a radius of $20 \mathrm{~km}$ ). This area is referred to below as isolated landscape.

\section{Captive Breeding}

We caught 69 adult females with eggsacs by hand (NHD: 22 females; FCD: 35 females; IDM: 12 females). Offspring were individually reared under standardized temperature $\left(20 \pm 2^{\circ} \mathrm{C}\right)$ and 16:8 $\mathrm{h}$ day:night regimes, and fed ad libitum with Sinella curviseta springtails until they reached the second postnatal instar.

\section{Propensity for Aerial Dispersal}

Prior to aerial dispersal, individuals of $P$. monticola and related species typically position themselves at an elevated starting point, stretch their legs, raise their abdomen and finally produce long silk threads that carry them up into the air currents. This stereotyped behaviour, termed 'tiptoe behaviour' (Weyman 1993; Weyman et al. 2002), can be quantified under standardized laboratory conditions following procedures described in Legel \& van Wingerden (1980) and Bonte et al. (2003b). Prior to experimental testing, we kept the spiderlings without food for 1 week to stimulate aerial dispersal under laboratory conditions (Bonte \& Maelfait 2001). For practical (time) reasons, we tested groups of five individuals at the same time because pilot experiments did not reveal effects of density during the tests on individual dispersal propensity (D. Bonte \& J. Vanden Borre, unpublished data). These groups were placed on a floating platform (to prevent cursorial escape) 
with a diameter of $4 \mathrm{~cm}$ that contained a series of vertical iron nails and was placed in a wind tunnel with upward current of $1-1.2 \mathrm{~m} / \mathrm{s}$, temperature of $30 \pm 2{ }^{\circ} \mathrm{C}$ and relative aerial humidity of 40-50\%. During 20-min observation sessions, we counted the spiderlings displaying tiptoe behaviour. Because we were not able to mark individual spiderlings, we removed those that performed tiptoe behaviour from each 20-min session to exclude pseudoreplication caused by double counting of the same individuals performing predispersal behaviour. We tested 2039 spiderlings, originating from 69 mothers (Table 1), for a total of $136 \mathrm{~h}$ observation time.

\section{Morphometrics}

As a measure of size of adult females and offspring, we multiplied the prosoma width by its length. We measured adult females on a binocular microscope (magnification $50 \times$ with measurement scale), and offspring with a digital image analyser. As size estimates did not differ between individuals that did or did not show tiptoe behaviour within each clutch (D. Bonte \& J. Vanden Borre, unpublished. data), we determined mean offspring size for each clutch. Because maternal size was correlated with mean offspring size (Pearson correlation: $r_{53}=0.41$, $P<0.001)$ and clutch size $\left(r_{53}=0.57, P<0.001\right)$, it reflected absolute reproductive output. Since maternal size was included as a covariate in all statistical models (Freckleton 2002), clutch size and offspring size reflected residual reproductive output.

\section{Statistical Analyses}

Variation in maternal size, offspring size and clutch size was analysed with general linear mixed models (GLMM, procedure mixed; SAS statistical package version 9.1) (SAS Institute Inc., Cary, NC, U.S.A.) with population as a fixed factor and subpopulation as a random factor. Presence or absence of tiptoe behaviour was analysed with mixed logistic regression models (procedure glimmix), taking into account unbalanced sampling designs. Fixed effects included characteristics of maternal reproduction and landscape type or patch for analyses between and within landscapes, respectively. The factor clutch (i.e. mother) was included as a random effect in all analyses. Denominator degrees of freedom were approximated by using Satterthwaite's procedure. We used nondirectional ordered heterogeneity test (Rice 1989; Rice \& Gaines 1994) to test variation in ballooning propensity in relation to patch size and connectivity within the fragmented landscape.

\section{RESULTS}

\section{Morphometry and Reproduction}

Maternal size (GLMM: $F_{2,36}=9.93, P=0.0004$ ), offspring size $\left(F_{2,31}=12.16, P=0.0001\right)$ and clutch size $\left(F_{2,36}=12.21, P=0.0001\right)$ differed significantly between the three landscape types (Table 1 ). For all traits, values were significantly higher in the continuous landscape than in fragmented and isolated ones (Tukey tests: $t>3.54$, all $P<0.01$ ), but did not vary between the fragmented and isolated landscapes $(t<0.85$, all NS). Within the fragmented landscape, maternal size $\left(F_{3,30}=1.58\right.$, NS), offspring size $\left(F_{3,21}=0.15\right.$, NS) and clutch size $\left(F_{3,30}=1.48\right.$, NS) did not differ between the four subpopulations.

\section{Ballooning Propensity}

\section{Between landscapes}

Tiptoe frequencies were significantly lower in the isolated landscape $(0.53 \%$, range $0-9.1 \%)$ than in the fragmented $(8.30 \%$, range $0-27 \%)$ and continuous ones (11.32\%, range $0-36.6 \%$; logistic mixed model: $F_{2,36}=7.01, \quad P=0.002$; Tukey test: $t>2.68, \quad P<0.05$; Fig. 1a). In the continuous landscape, tiptoe frequency was significantly higher than in the fragmented landscape $(t>2.11, P<0.05)$. Maternal size, offspring size and clutch size did not explain additional variation in tiptoe frequency (Wald $\chi_{1}^{2}<2.56$, NS). Between-clutch variation was low as well (variance $s^{2} \pm \mathrm{SE}=0.197 \pm 0.205$ ).

\section{Within landscapes}

Within the fragmented landscape, tiptoe frequencies differed significantly between the four subpopulations $\left(F_{2,31}=4.10, P=0.026\right.$; Fig. $\left.1 \mathrm{~b}\right)$ and increased with patch area/connectivity (ordered heterogeneity test: $r_{\mathrm{S}}=1$, $P_{\mathrm{c}}=0.974, P<0.001$; Rice \& Gaines 1994). However, because patch area covaried strongly with patch connectivity (see above) we cannot distinguish between the two landscape effects. None of the traits related to maternal reproduction explained additional variation (all $F<1.56$,

Table 1. Mean \pm SE maternal size, offspring size and clutch size in six P. monticola populations inhabiting continuous, fragmented and isolated landscapes

\begin{tabular}{|c|c|c|c|c|c|c|}
\hline & \multirow[b]{2}{*}{ Continuous } & \multicolumn{4}{|c|}{ Fragmented } & \multirow[b]{2}{*}{ Isolated } \\
\hline & & 1 & 2 & 3 & 4 & \\
\hline No. of females & 22 & 9 & 11 & 8 & 7 & 12 \\
\hline Maternal size $\left(\mathrm{mm}^{2}\right)$ & $5.01 \pm 0.11$ & $4.09 \pm 0.16$ & $3.21 \pm 0.10$ & $4.55 \pm 0.17$ & $4.04 \pm 0.21$ & $4.22 \pm 0.19$ \\
\hline Offspring size (mm) & $2.48 \pm 0.02$ & $2.33 \pm 0.02$ & $2.35 \pm 0.03$ & $2.34 \pm 0.03$ & $2.36 \pm 0.02$ & $2.28 \pm 0.03$ \\
\hline Clutch size & $44.10 \pm 2.17$ & $27.75 \pm 4.18$ & $21.63 \pm 3.28$ & $36.87 \pm 3.28$ & $24.85 \pm 7.46$ & $27.50 \pm 2.27$ \\
\hline
\end{tabular}




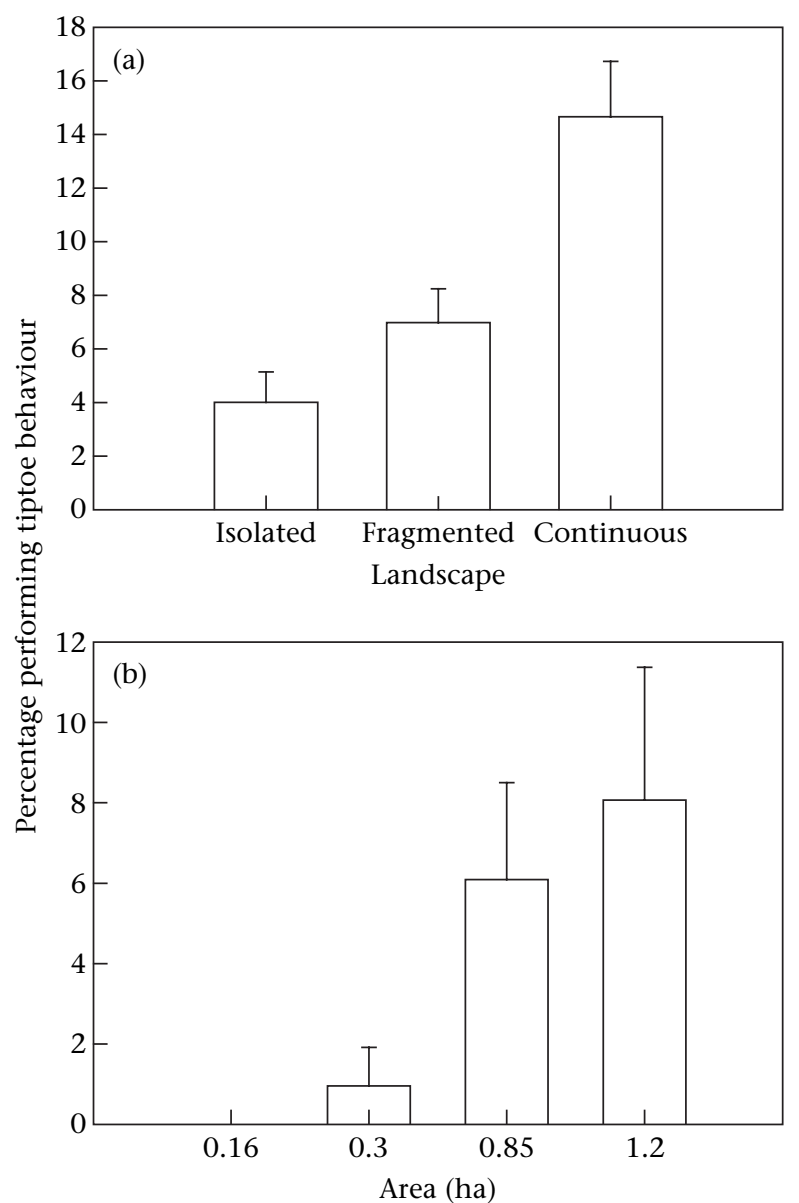

Figure 1. Mean percentage of individuals per clutch + SE performing tiptoe behaviour within (a) continuous, fragmented and isolated dune landscapes and (b) from a fragmented landscape in which patch connectivity covaried strongly with patch size; see text.

NS), and between-clutch variation was again very low $\left(s^{2} \pm \mathrm{SE}=0.069 \pm 1.213\right)$.

\section{DISCUSSION}

We used a standardized laboratory setting to study geographical variation in propensity for aerial dispersal, that is, through comparison of tiptoe behaviour in P. monticola offspring reared from females captured in dune grasslands, varying in patch area and connectivity. Offspring from a continuous landscape were most likely to perform tiptoe behaviour and offspring from small and isolated grasslands were least likely. At the scale of a single (fragmented) landscape, dispersal propensity was also positively related to patch size and connectivity. As patch size and connectivity covaried strongly in our study, we cannot distinguish between these effects. Effects of maternal reproductive characteristics on tiptoe behaviour were small. Regardless of the underlying evolutionary background, this study is the first to demonstrate geographical and interdemic variation in aerial dispersal by spiders and extends our knowledge on the evolution of passive dispersal, which rarely has been documented for animals.

\section{Geographical Variation Caused by Maternal Effects?}

The observed relation between tiptoe behaviour and landscape configuration is concordant with the general prediction from dispersal theory that emigration will be counterselected when the probability of reaching suitable habitat is low (Dieckmann et al. 1999). Variation in tiptoe behaviour, in which individual responses relate to environmental conditions, may arise from ultimate (evolutionary) as well as proximate factors (i.e. environmentally triggered dispersal). As the spiderlings used in the experiments had no experience of their natal environment, a direct environmental effect can be excluded, although an environmental effect through maternal (conditional) effects remains possible (Ims \& Hjermann 2001; Bowler \& Benton 2005). Condition-dependent dispersal is generally believed to occur in competitively inferior individuals (i.e. poor-condition ones; Lawrence 1987; Léna et al. 1998). An alternative possibility for condition-dependent dispersal, however, is that spiderlings originating from large populations (i.e. goodcondition ones) show a higher dispersal tendency, since immigration into new competitive environments requires energetic reserves (Gundersen et al. 2002). In this way, condition per se is a possible trigger for higher dispersal in spiders originating from large, continuous landscapes. Sex ratio distortion may also influence natal dispersal rates (Ims 1990). Since we did not record any bias in sex ratio within populations (D. Bonte, unpublished data), this mode of condition-dependent dispersal is, however, unlikely (Ims 1990). Condition-dependent dispersal, in contrast to selection-based dispersal, is believed to be expressed at the individual level, that is, within populations (Gundersen et al. 2002). Because our patterns of dispersal could not be related to individual condition (i.e. variation within populations) or to differences in maternal fitness and individual body size between subpopulations of the fragmented landscape and between populations of fragmented and isolated landscapes, condition-dependent dispersal is unlikely.

Nevertheless, the observed relation between aerial dispersal, isolation and size of the fragments within a single metapopulation, as well as the absence of any relation with maternal reproductive condition, does not exclude alternative mechanisms for rapid microevolutionary change, as landscapes may differ in various aspects of habitat quality that may induce a maternal effect on offspring dispersal. For instance, egg quality (lipids, proteins) may be affected by female physiology, as shown in the gypsy moth, Lymantria dispar (Diss et al. 1996), and may result in different threshold levels for dispersal behaviour in populations inhabiting different types of habitat.

\section{Passive versus Active Dispersal}

The passive nature of ballooning dispersal renders the selection-based view on dispersal behaviour even more likely. Selection pressures caused by habitat fragmentation may shape dispersal behaviour differently in 'active' and 'passive' dispersers. Active dispersers generally have 
well-developed locomotor and sensory systems enabling them to control movement trajectories and to settle in suitable habitat (e.g. Schooley \& Wiens 2003; Van Dyck \& Baguette 2005). In arthropod species that disperse passively through wind currents (or water currents, e.g. marine species, Hiddink et al. 2002), dispersal trajectories will depend entirely on physical drag properties (i.e. vertical and horizontal directionality, strength) of the currents, individual morphology (body posture, mass) and length of the silk threads (if necessary to generate sufficient drag). Flight control also assumes the presence of sensory systems for environmental perception, but olfaction and vision are weakly developed even at small distances in actively hunting arthropod species with passive aerial dispersal (Bonte et al. 2004).

Regardless of whether individuals are able to change velocity by adjusting postures (Suter 1992) or thread lengths (Bell et al. 2005), the nature of the currents remains intrinsically unpredictable. As a consequence, the uncertainty of reaching suitable habitat remains high when individuals take the decision to disperse. In conclusion, active dispersers are most probably characterized by 'percolation' or 'nearest-neighbour' dispersal (e.g. Wiens et al. 1993, 1995, 1997; Schtickzelle \& Baguette 2003), whereas passive dispersal can be considered to be a random event (With \& King 1999; King \& With 2002). Based on spatially explicit population models, King \& With (2002) predicted that costs associated with random dispersal are highest in rare, fragmented habitats, as is the case with dune grasslands (e.g. Collinge 2000). Consequently, costs of dispersal, being related to the chances of reaching suitable habitat, can be expected to be much higher for passive than active dispersers (With et al. 1997). As a result, habitat fragmentation is likely to select predominantly against dispersal (behaviour) in passive dispersers, whereas in active, winged dispersers with well-developed perception of the environment, selection for dispersal can be expected (e.g. Taylor \& Merriam 1995; Hill et al. 1996; Desender et al. 1998).

In arthropod species such as butterflies with more active and controlled dispersal behaviour, Van Dyck \& Baguette (2005) suggested that apparent dispersal patterns may well be by-products of routine movements associated with daily activities such as foraging and mate location. This may partly explain the apparent heterogeneous effects of habitat fragmentation on 'dispersal' in these organisms (e.g. Taylor \& Merriam 1995; Hill et al. 1996; Hanski et al. 2004). Apart from species that show clear morphological (e.g. wings in aphids and waterstriders; Zera \& Denno 1997) or behavioural dispersal properties (e.g. unique predispersal behaviour in spiders, mites and caterpillars; Bell et al. 2005), morphological variation (e.g. in wing size) between populations probably does not reflect selection for dispersal, but rather relates to thermoregulation (Kemp \& Krockenberger 2004), predator avoidance (Rydell \& Lancaster 2000) or selection for other genetically correlated traits (Roff 1997; Mazer \& Damuth 2001). Evidence suggests that actively moving arthropods perform special dispersal behaviours (e.g. fast movements, high linearity of the trajectory configuration; Van Dyck \& Baguette 2005; Communications Arthropod dispersal workshop, Wuerzburg University, September 2005), but remains mainly anecdotal.

\section{Selection against Dispersal}

As subdivision of the $P$. monticola population in the fragmented landscape dates back to the early 1980s, fast interdemic microevolution of aerial dispersal (or an adjustment of the behavioural threshold to perform dispersal) may have occurred in relation to recent fragmentation of short grasslands in the dune landscape (Provoost et al. 2004). A similar case of reduced dispersal propensity has been described in weedy, short-lived and wind-dispersed plants of inshore islands in Canada (Cody \& Overton 1996). As shown by Desender et al. (1998) and Hanski et al. (2004), dispersal may be higher in young populations because of founder effects. In our case, however, populations of the continuous and isolated landscapes are probably the oldest ones because of historical formation of the landscape, while those from the fragmented landscape contain potentially the youngest population that has been recently fragmented (Bonte et al. 2003a). As (potential) age of populations did not relate to dispersal propensity, this factor was probably less important than landscape structure. Population size also covaried with patch size and isolation (Bonte et al. 2003a), so the reduction in population sizes and resulting increase in inbreeding may influence dispersal propensity rather than patch configuration per se. As shown by Donohue (1998) and Bilde et al. (2005), inbreeding potentially reduces developmental stability and may result in inbreeding depression, potentially affecting dispersal strategies. Dispersal can also be under direct genetic influence if inbreeding increases homozygosity of deleterious recessive genes that are linked to dispersal behaviour (associative overdominance; Maynard Smith 1998).

\section{Effect on Gene Flow}

In contrast to cursorial dispersal in spiders, in which only small distances are covered, ballooning dispersal is the main dispersal mode responsible for gene flow in landscapes where the matrix does not allow more active dispersal (e.g. cursorial movements, Bonte et al. 2003c). Because costs associated with dispersal in fragmented landscapes depend on both dispersal ability (i.e. the distance an individual is likely to cover during its lifetime) and dispersal control (including perceptual ability), loss of genetic diversity within spatially structured populations of passive dispersers is likely to be greater than in active dispersers, whereas genetic differentiation can be expected to be higher, hence increasing the probability of speciation (Gavrilets 2004). As shown by our data, genetic diversity in isolated populations can be expected to decrease through both reduced population sizes (as a result of the combined effect of habitat area and decreased reproduction) and the loss of dispersal behaviour. In the case of $P$. monticola, genetic diversity was twice as high in the continuous as in the fragmented dune landscape (Bonte et al. 2003c). Although convincing empirical validation of 
dispersal-mode-dependent population genetic structure is lacking, passively dispersing arthropods from discontinuous and fragmented habitats appear to be more vulnerable to genetic erosion than their actively dispersing counterparts. High levels of (behavioural) speciation within spiders (e.g. McClintock \& Uetz 1996; Miller et al. 1998; Töpfer-Hofmann et al. 2000) substantiate the expectation of high genetic differentiation in fragmented habitat types (e.g. forests, oligotrophic grasslands, salt marshes).

\section{Conclusion}

Our experiments indicate that reduction of suitable habitat in combination with fragmentation may lead to a decrease in dispersal rates, possibly because of the loss of genes associated with dispersal in isolated populations (Dieckmann et al. 1999). This pattern is consistent at both small and large spatial scales. Variation in aerial dispersal propensity could not be attributed to maternal effects through reproduction, although maternal condition and aerial dispersal covaried at the population level among the three dune landscapes. Apart from changes in morphological design, habitat fragmentation as such (Schooley \& Wiens 2004) may thus induce selection pressures that affect behavioural traits closely linked to dispersal and hence lead to reduced mobility and gene flow (e.g. Thomas et al. 1998; Van Dyck \& Matthysen 1999; Hanski et al. 2002). Furthermore, our results suggest that selection forces in fragmented habitats can alter within-species dispersal propensity in a similar way as between species (Bonte et al. 2003d), indicating that microevolutionary changes in aeronautical behaviour can overrule evolutionary changes at the species level. This is confirmed by similar ranges of ballooning propensity between Pardosa wolf spiders (Richter 1970), compared to variation within $P$. monticola.

\section{Acknowledgments}

We thank our colleague Dr F. Hendrickx for statistical advice. Dr R. H. Slotow and an anonymous referee gave valuable comments on the manuscript. D.B. is a postdoctoral fellow of the Foundation of Scientific Research, Flanders (FWO).

\section{References}

Arnold, S. J. 1992. Behavioural variation in natural populations. VI. Prey responses by two species of garter snakes in three regions of sympatry. Animal Behaviour, 44, 705-719.

Bell, J. R., Bohan, D. A., Shaw, E. M. \& Weyman, G. S. 2005. Ballooning dispersal using silk: world fauna, phylogenies, genetics and models. Bulletin of Entomological Research, 95, 69-114.

Bilde, T., Lubin, Y., Smith, D., Schneider, J. M. \& Maklakov, A. A. 2005. The transition to social inbred mating systems in spiders: role of inbreeding tolerance in a subsocial predecessor. Evolution, 59, 160-174.

Bonte, D. \& Maelfait, J.-P. 2001. Life history, habitat use and dispersal of a dune wolf spider (Pardosa monticola (CLERCK 1757) Lycosidae, Araneae) in the Flemish coastal dunes (Belgium). Belgian Journal of Zoology, 131, 141-153.
Bonte, D., Criel, P., Van Thournout, I. \& Maelfait, J.-P. 2003a. Regional and local variation of spider assemblages (Araneae) from coastal grey dunes along the North Sea. Journal of Biogeography, 30, 901-911.

Bonte, D., De Blauwe, I. \& Maelfait, J.-P. 2003b. Environmental and genetic background of variation in tiptoe-initiating behaviour in a dwarfspider (Erigone atra (Araneae: Linyphiidae)). Animal Behaviour, 66, 169-174.

Bonte, D., Lens, L., Maelfait, J.-P., Hoffmann, M. \& Kuijken, E. 2003c. Patch quality and connectivity influence spatial dynamics in a dune wolfspider. Oecologia, 135, 227-233.

Bonte, D., Vandenbroecke, N., Lens, L. \& Maelfait, J.-P. 2003d. Low propensity for aerial dispersal in specialist spiders from fragmented landscapes. Proceedings of the Royal Society of London, Series B, 270, 1601-1607.

Bonte, D., Lens, L. \& Maelfait, J.-P. 2004. Lack of homeward orientation and increased mobility result in high emigration rates from low-quality fragments in a dune wolf spider. Journal of Animal Ecology, 73, 643-650.

Bowler, D. E. \& Benton, T. G. 2005. Causes and consequences of animal dispersal strategies: relating individual behaviour to spatial dynamics. Biological Reviews, 80, 205-225.

Bullock, J. M., Kenward, R. E., Hails, R. S. (Eds). 2002. Dispersal Ecology. Oxford: Blackwell.

Carlquist, S. 1966. The biota of long-distance dispersal. II. Loss of dispersability in the Pacific Compositae. Evolution, 20, 30-48.

Clobert, J., Danchin, E., Dhondt, A. A., Nichols, J. D. (Eds). 2001. Dispersal. Oxford: Oxford University Press.

Cody, M. L. \& Overton, J. M. 1996. Short-term evolution of reduced dispersal in island plant populations. Journal of Ecology, 84, 53-61.

Collinge, S. K. 2000. Effects of grassland fragmentation on insect species loss, recolonization, and movement patterns. Ecology, 81, 2211-2226.

De Fraipont, M., Clobert, J., John-Alder, H. \& Meylan, S. 2000. Increased prenatal maternal corticosterone promotes philopatry of offspring in common lizards Lacerta vivipara. Journal of Animal Ecology, 69, 404-413.

Den Boer, P. J. 1970. On the significance of dispersal power for populations of carabid beetles (Coleoptera, Carabidae). Oecologia, 4, $1-28$.

Desender, K., Backeljau, T., Delahaye, K. \& De Meester, L. 1998. Age and size of European saltmarshes and the population genetic consequences for ground beetles. Oecologia, 114, 503513.

Dieckmann, U., O'Hara, B. \& Weiser, W. W. 1999. The evolutionary ecology of dispersal. Trends in Ecology and Evolution, 14, 8894.

Dingle, H. 1996. Migration. The Biology of Life on the Move. New York: Oxford University Press.

Diss, A. L., Kunkel, J. G., Montgomery, M. E. \& Leonard, D. E. 1996. Effects of maternal nutrition and egg provisioning on parameters of larval hatch, survival and dispersal in the gypsy moth, Lymantria dispar L. Oecologia, 106, 470-477.

Donohue, K. 1998. Effects of inbreeding on traits that influence dispersal and progeny density in Cakile edentula var. Lacustris (Brassicaceae). American Journal of Botany, 85, 661-668.

Foster, S. A. 1999. The geography of behaviour: an evolutionary perspective. Trends in Ecology and Evolution, 14, 190-195.

Freckleton, R. P. 2002. On the misuse of residuals in ecology: regression of residuals vs. multiple regression. Journal of Animal Ecology, 71, 542-545.

Gavrilets, S. 2004. Speciation in metapopulations. In: Ecology, Genetics and Evolution of Metapopulations (Ed. by I. Hanski \& O. E. Gaggiotti), pp. 259-274. Amsterdam: Elsevier. 
Greenwood, P. J., Harvey, P. H. \& Perrins, C. M. 1978. Inbreeding and dispersal in great tit. Nature, 271, 52-54.

Gundersen, G., Andreassen, H. P. \& Ims, R. A. 2002. Individual and population-level determinants of immigration success on local habitat patches: an experimental approach. Ecology Letters, 5, 294-301.

Hanski, I., Breuker, C. J., Schöps, K., Setchfield, R. \& Nieminen, M. 2002. Population history and life history influence the migration rate of female Glanville fritillary butterflies. Oikos, 98, 87-97.

Hanski, I., Erälahti, C., Kankare, M., Ovaskainen, O. \& Siren, H. 2004. Variation in migration propensity among individuals maintained by landscape structure. Ecology Letters, 7, 958-966.

Hendrickx, F., Maelfait, J. P. \& Lens, L. 2003. Relationship between fluctuating asymmetry and fitness within and between stressed and unstressed populations of the wolf spider Pirata piraticus. Journal of Evolutionary Biology, 16, 1270-1279.

Hiddink, J. G., Kock, R. P. \& Wolff, W. J. 2002. Active pelagic migrations of the bivalve Macoma balthica are dangerous. Marine Biology, 140, 1149-1156.

Hill, J. K., Thomas, C. D. \& Lewis, O. T. 1996. Effects of habitat patch size and isolation on dispersal by Hesperia comma butterflies: implications for metapopulation structure. Journal of Animal Ecology, 65, 725-735.

Ims, R. A. 1990. Determinants of natal dispersal and space use in grey-sided voles, Clethrionomys rufocanus: a combined field and laboratory experiment. Oikos, 57, 106-113.

Ims, R. A. \& Hjermann, D. O. 2001. Condition-dependent dispersal. In: Dispersal (Ed. by J. Clobert, E. Danchin, A. A. Dhondt \& J. D. Nichols), pp. 203-216. Oxford: Oxford University Press.

Kemp, D. J. \& Krockenberger, A. K. 2004. Behavioural thermoregulation in butterflies: the interacting effects of body size and basking posture in Hypolimnas bolina (L.) (Lepidoptera: Nymphalidae). Australian Journal of Zoology, 52, 229-236.

King, A. W. \& With, K. A. 2002. Dispersal success on spatially structured landscapes: when do spatial pattern and dispersal behaviour really matter? Ecological Modelling, 147, 23-39.

Komonen, A., Grapputo, A., Kaitala, V., Kotiaho, J. S. \& Païvinen, J. 2004. The role of niche breadth, resource availability and range position on the life history of butterflies. Oikos, 105, 41-54.

Lawrence, W. S. 1987. Dispersal and alternative mating tactic conditional on sex-ratio and body size. Behavioral Ecology and Sociobiology, 57, 21-35.

Legel, G. J. \& van Wingerden, W. K. R. E. 1980. Experiments on the influence of food and crowding on the aeronautic dispersal of Erigone arctica (WHITE 1852) (Araneae, Linyphiidae). In: Proceedings of the 8th International Congress of Arachnology, Vienna, July 1979 (Ed. by J. Grüber), pp. 97-103. Vienna: Verlag H. Egerman.

Léna, J. P., Clobert, J., de Fraipont, M., Lemcompte, J. \& Guyot, G. 1998. The relative influence of density and kinship on dispersal in the common lizard. Behavioral Ecology, 9, 500-507.

Li, J. \& Margolies, D. C. 1993. Quantitative genetics of aerial dispersal behaviour and life-history traits in Tetranychus urticae. Heredity, 70, 544-552.

Li, J. \& Margolies, D. C. 1994. Responses to direct and indirect selection on aerial dispersal behaviour in Tetranychus urticae. Heredity, 72, 10-22.

McClintock, W. J. \& Uetz, G. W. 1996. Female choice and preexisting bias: visual clues during courtship in two Schizocosa wolf spiders (Araneae: Lycosidae). Animal Behaviour, 52, 167-181.

Massot, M. \& Clobert, J. 2000. Processes at the origin of similarities in dispersal behaviour among siblings. Journal of Evolutionary Biology, 13, 707-719.

Maynard Smith, J. 1998. Evolutionary Genetics. Oxford: Oxford University Press.
Mazer, S. J. \& Damuth, J. 2001. Evolutionary significance of variation. In: Evolutionary Ecology, Concepts and Case Studies (Ed. by C. W. Fox, D. A. Roff \& D. J. Fairbairn), pp. 16-28. Oxford: Oxford University Press.

Miller, G. L., Stratton, G. E., Miller, R. M. \& Hebets, E. 1998. Geographical variation in male courtship behaviour and sexual isolation in wolf spiders of the genus Schizocosa. Animal Behaviour, 56, 937-951.

Negro, J. J., Hinaldo, F. \& Donazer, J. A. 1997. Causes of natal dispersal in the lesser kestrel: inbreeding avoidance or resource competition? Journal of Animal Ecology, 66, 640-648.

Provoost, S., Ampe, C., Bonte, D., Cosyns, E. \& Hoffmann, M. 2004. Ecology, management and monitoring of dune grasslands in Flanders, Belgium. Journal of Coastal Conservation, 10, 33-42.

Rice, W. R. 1989. Analyzing tables of statistical tests. Evolution, 43, 223-225.

Rice, W. R. \& Gaines, S. D. 1994. Extending nondirectional heterogeneity tests to evaluate simply ordered alternative hypotheses. Proceedings of the National Academy of Sciences, U.S.A., 91, 225-226.

Richter, C. J. 1970. Aerial dispersal in relation to habitat in eight wolf spider species (Pardosa, Araneae, Lycosidae). Oecologia, 5, 200-214.

Riechert, S. E. 1999. The use of behavioural ecotypes in the study of evolutionary processes. In: Geographic Variation in Behavior: Perspectives and Evolutionary Mechanisms (Ed. by S. A. Foster \& J. A. Endler), pp. 3-32. New York: Oxford University Press.

Roff, D. A. 1997. The evolution of threshold traits: a quantitative genetic analysis of the physiological and life history correlates of wing dimorphism in the land cricket. Evolution, 51, 1910-1919.

Rydell, J. \& Lancaster, W. C. 2000. Flight and thermoregulation in moths were shaped by predation from bats. Oikos, 88, 13-18.

Schooley, R. L. \& Wiens, J. A. 2003. Finding habitat patches and directional connectivity. Oikos, 102, 559-570.

Schooley, R. L. \& Wiens, L. A. 2004. Movement of cactus bugs: patch transfer, matrix resistance, and edge permeability. Landscape Ecology, 19, 801-810.

Schtickzelle, N. \& Baguette, M. 2003. Behavioural responses to habitat patch boundaries restrict dispersal and generate emigration-patch area relationships in fragmented landscapes. Journal of Animal Ecology, 72, 533-545.

Sorci, G., Massot, M. \& Clobert, J. 1994. Maternal parasite load increases sprint speed and philopatry in female offspring of the common lizard. American Naturalist, 144, 153-166.

Southwood, T. R. E. 1962. Migration of terrestrial arthropods in relation to habitat. Biological Reviews, 37, 171-214.

Suter, R. B. 1992. Ballooning: data from spiders in freefall indicate the importance of posture. Journal of Arachnology, 20, 107-113.

Taylor, P. D. \& Merriam, G. 1995. Wing morphology of a forest damselfly is related to landscape structure. Oikos, 73, 43-48.

Thomas, C. D., Hill, J. K. \& Lewis, O. T. 1998. Evolutionary consequences of habitat fragmentation in a localised butterfly. Journal of Animal Ecology, 67, 485-497.

Toft, S. 1999. Prey choice and spider fitness. Journal of Arachnology, 27, 301-307.

Töpfer-Hofmann, G., Cordes, D. \& von Helversen, O. 2000. Cryptic species and behavioural isolation in the Pardosa lugubris group (Araneae, Lycosidae), with description of two new species. Bulletin of the British Arachnological Society, 11, 257-274.

Van Dyck, H. \& Baguette, M. 2005. Dispersal behaviour in fragmented landscapes: routine or special movements? Basic and Applied Ecology, 6, 535-545.

Van Dyck, H. \& Matthysen, E. 1999. Habitat fragmentation and insect flight: a changing 'design' in a changing landscape? Trends in Ecology and Evolution, 14, 172-174. 
Weyman, G. S. 1993. A review of the possible causative factors and significance of ballooning in spiders. Ethology, Ecology and Evolution, 5, 279-291.

Weyman, G. S., Jepson, P. C. \& Sunderland, K. D. 1995. Do seasonal changes in numbers of aerially dispersing spiders reflect population density on the ground or variation in ballooning motivation? Oecologia, 101, 487-493.

Weyman, G. S., Sunderland, K. D. \& Jepson, P. C. 2002. A review of the evolution and mechanisms of ballooning by spiders inhabiting arable farmland. Ethology, Ecology and Evolution, 14, 307-326.

Wiens, J. A., Crist, T. O. \& Milne, B. T. 1993. On quantifying insect movements. Environmental Entomology, 22, 709-715.

Wiens, J. A., Crist, T. O. \& Milne, B. T. 1995. Fractal patterns of insect movement in microlandscape mosaics. Ecology, 76, 663-666.
Wiens, J. A., Schooley, R. L. \& Weeks, R. D., Jr. 1997. Patchy landscapes and animal movements: do beetles percolate? Oikos, 78, 257-264.

With, K. A. \& King, A. W. 1999. Dispersal success on fractal landscapes: a consequence of lacunarity thresholds. Landscape Ecology, 14, 73-82.

With, K. A., Gardner, R. H. \& Turner, M. G. 1997. Landscape connectivity and population distributions in heterogeneous environments. Oikos, 78, 151-169.

Zera, A. J. \& Denno, R. F. 1997. Physiology and ecology of dispersal polymorphism in insects. Annual Review of Entomology, 42, 207231.

Zumkehr, P. 2001. Een Vegetatiekartering van de Wimmenummerduinen bij Egmond. Onderzoeksrapport 2001-1. Castricum: PWN Waterleidingsbedrijf Nzoord-Holland. 